\title{
Flow visualization of the jet exiting a chevron nozzle
}

\begin{abstract}
An experimental investigation has been carried out to visualize the jet development, issuing from chevron nozzles, for a Reynolds number of 25000 . Flow visualization was performed by laser illumination on the Titanium Tetrachloride smoke to visualize jet structure at different cross-sections along the jet axis; which was used to study the behavior of the flow development. Pitot pressure measurements were also carried out along the jet centreline in the near-field, to quantify the potential core and characteristic decay of the jets. The flow features reveals that, the non-axisymmetric structure of the jet results in enhanced mixing of the jet. It is also evident from the Pitot measurement that, the reduction in potential corelength is appreciable for both the chevron configurations, implying that the ability of the chevron to break down large scale coherent structures to refine the small-scale mixing of the jet. Moreover, it is also found that the number of the chevron tooth has a pronounced effect on the mixing characteristics.
\end{abstract}

Volume 2 Issue 2 - 2018

\author{
Nandita NH,' Sruthi R,' Suriyaprabha,' \\ Meenakshi Sundaram,' Arun Kumar P' \\ 'Undergraduate Student, Department of Aerospace Engineering, \\ Amrita University, India \\ ${ }^{2}$ Assistant Professor, Department of Aerospace Engineering, \\ Amrita University, India
}

Correspondence: Arun Kumar P,Assistant Professor, Department of Aerospace Engineering,Amrita University, Coimbatore-64I I I2, India, Email arunaero03@gmail.com

Received: October 28, 2017 | Published: March 23, 2018

Keywords: Flow visualization, Chevron nozzles, Subsonic jet control, axi-symmetric structure.

\section{Introduction and motivation}

Control of jets has been studied for over a century and even today continues to be a significant research topic. It finds applications in various fields especially in aerospace, where enhancement of mixing characteristics of a jet can improve the performance greatly. Review articles by Gutmark et al.; ${ }^{1}$ Gutmark \& Grinstein; ${ }^{2}$ Seiner et al.; ${ }^{3}$ Glezer \& Amitay; ${ }^{4}$ Reynolds et al., ${ }^{5}$ Ginevsky Vlasov \& Karavosov; ${ }^{6}$ Knowles \& Saddington; ${ }^{7}$ Henderson, ${ }^{8}$ provide an excellent survey of mixing enhancement techniques. In general all types of control can be broadly classified into active and passive controls. In active control, an auxiliary power source, for example, fluid tabs ${ }^{9-17}$ is used to control the jet characteristics. On the other hand, passive control finds its importance in the research area due to its simple geometric modification, leading the mixing enhancement without requiring any power source, such as non-circular nozzles, ${ }^{2,18}$ implementation of tooth like tabs ${ }^{19-24}$ and chevron nozzles. ${ }^{25-31}$ In spite of the extensive study of tabs and non-circular nozzles, they have lost its scope while implementing on practical situations because of its disadvantages. Once tabs are mounted, they are prone to erosion, induce thrust loss, increase in base drag and making the jet to become asymmetry. ${ }^{18}$ Frequent implementation of non-circular nozzles causes very high cost and requires a very aft-duct. Both tabs and non-circular nozzles cause the jet structure to become non-axisymmetric, thereby increasing the mixing of the jet with the ambient. So, the underlying phenomenon is that the mixing increases if the jet is non-axisymmetric. Hence the alternate passive control technique which overcomes the disadvantage of tabs and non-circular nozzles is the IChevrons". Chevrons, a saw tooth pattern on the trailing edge of exhaust nozzles, are being implemented on modern jet engines is one of the most popular passive control device in the recent years.

Chevrons were basically extensions of the nozzle wall into a continuous serrated edge. ${ }^{29}$ With serrated trailing edge geometry, chevron nozzles enhance the mixing between adjacent streams, reducing the velocity gradient across the jet plume. ${ }^{32}$ In the past few years, quite a few experimental and numerical simulations had been performed to assess the mixing and acoustic capability of the chevron jet. ${ }^{25-31}$ The evolution of the jet structure from the chevron nozzles, which leads to a mixing enhancement, is yet to be studied. Whether the introducing a chevron results in an axisymmetric jet on a nonaxisymmetric jet, is yet to be fully understood. Naturally a question arises. How does the behavior of the nature of jet structure results in jet mixing? To address these issues, an experimental investigation has been carried out on the jet issuing from a chevron nozzle. To visualize the jet structure emanating from the chevron nozzles, experiments had been carried out for a jet Reynoldss number of 25,000. Flow visualization was performed by laser illumination on the Titanium Tetrachloride smoke injected through the jet apparatus. The structure of the jet at different cross-sections was used to study the behavior of the jets. Also, to analyze the influence of the number of chevron tooth on the jet mixing characteristics, Pitot pressure measurement were carried out along the jet centreline in the near-field, to quantify the effect of chevron tooth on the potential core and characteristic decay of the jets.

\section{Experimental setup}

The experiments for the present study were conducted in Propulsion Laboratory at Amrita School of Engineering, Coimbatore. The test facility consists of the setup which includes air supply (compressors and storage tanks) and open jet testing facility with provision to change the exit condition. The air supply system consists of a reciprocating compressor capable of delivering $0.043 \mathrm{~kg} / \mathrm{s}$ of air at a pressure of $10 \mathrm{~N} / \mathrm{m}^{2}$. The compressor is driven by a $7.5 \mathrm{~kW}$ threephase induction motor. The compressed air gets stores in the tank of $11.30 \mathrm{~m}^{3}$ volume which is then driven through a main control valve and fed into the setup using a diaphragm type back pressure valve. The schematic layout of the open jet test facility is shown in Figure 1.

The setup consists of a cylindrical settling chamber connected to the main tank through a conical diverging section, which ensures the flow entering the settling chamber with less turbulence. A Gate valve which controls the compressed air from the storage tank to the settling chamber is placed at sufficient distance of $1.5 \mathrm{~m}$ upstream of the chamber inlet, so as to reduce the flow disturbance caused the valve. The settling chamber is $63.5 \mathrm{~cm}$ in length and has a constant circular cross-section of diameter $15 \mathrm{~cm}$. A control valve present at the entry of 
diffuser section is used to regulate the settling chamber pressure. The settling chamber has a tapping for stagnation pressure measurements. The test model is mounted to the end of the settling chamber with the help of a base plate. The stagnation pressure $\mathrm{p}_{0}$, controlled by the pressure regulating valve (control valve), is maintained a constant throughout the experiment with an uncertainty of $\pm 0.01 \%$. The settling chamber temperature $\left(\mathrm{T}_{0}\right)$ is the same as the ambient temperature and the back pressure $\left(p_{b}\right)$ to which the jet is discharged is the ambient pressure. In the present work, the ambient pressure $\left(\mathrm{p}_{\mathrm{a}}\right)$ was measured by a Arduino and the uncertainty associated in the measurement of atmospheric pressure is about $\pm 0.01 \%$.

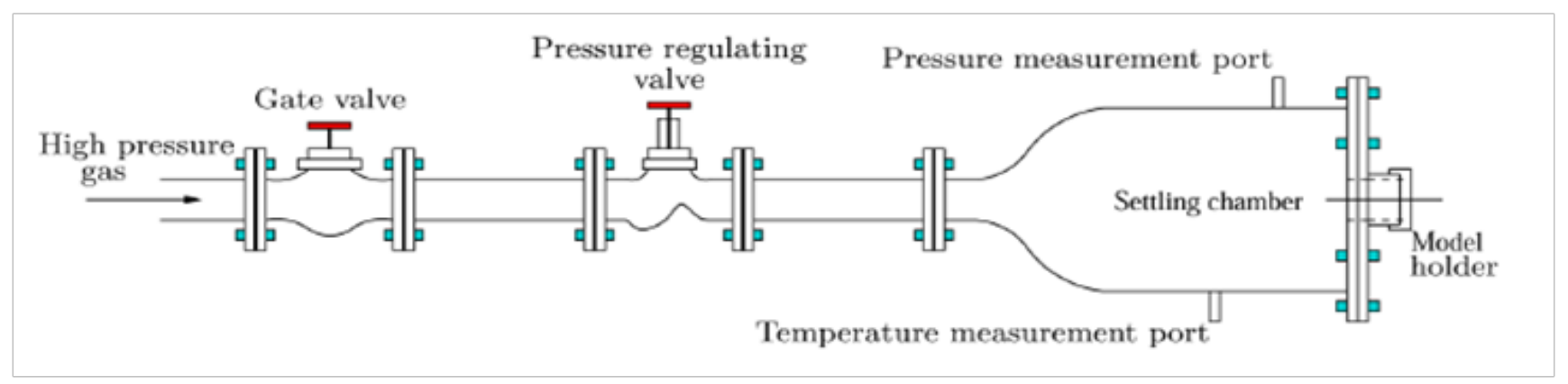

Figure I Schematic layout of the open jet facility.

The present investigation also aims to compare the near-field mixing of chevron nozzles with the conventional circular nozzle. The experimental model is axi-symmetric conventional circular nozzle of length $66.02 \mathrm{~mm}$ and exit diameter of $12.02 \mathrm{~mm}$, with a converging angle of 17 degrees, made of brass. Chevron tooth's were removed from the nozzle and it is ensured that the exit diameter of all chevron nozzles to be the same that of conventional circular nozzle (Figure 2).
Six-tooth and eight-tooth chevrons nozzle has a tooth projection of about $13 \mathrm{~mm}$ each, towards the nozzle inlet. The Reynolds numbers of the jet coming out of the nozzle is about 25000 for the present investigation. The Reynolds number, $\operatorname{Re}_{\mathrm{d}}$, is based on $\rho_{\mathrm{j}}, \mathrm{U}_{\mathrm{j}}, \mathrm{D}$ and $\mu_{\mathrm{j}}$ where $U_{j}$ is the jet velocity, $\rho_{\mathrm{j}}$ is determined using isentropic relation and $\mu_{\mathrm{j}}$ is calculated based on Sutherland's formula.

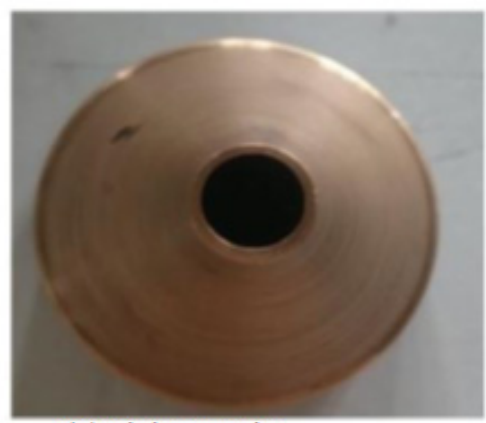

(a) Plain nozzle

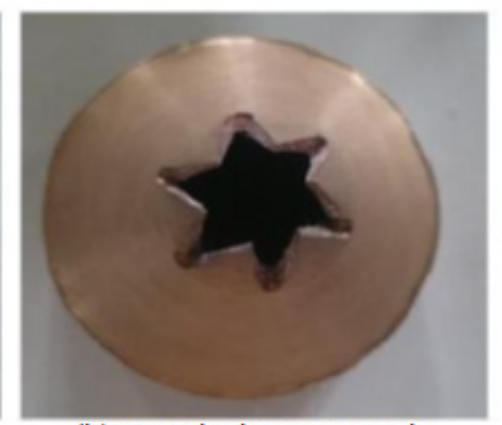

(b) 6 tooth chevron nozzle

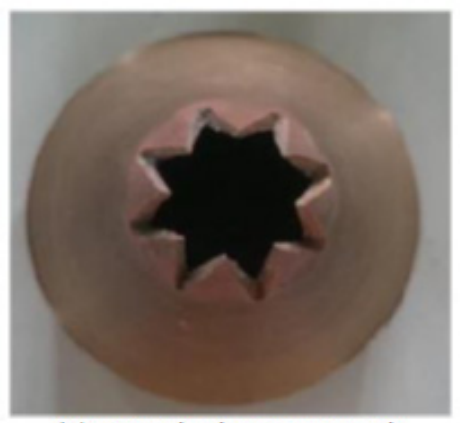

(c) 8 tooth chevron nozzle

Figure 2 Photograph of the nozzles.

The pressure measurement in the jet was done using a Pitot tube of $0.4 \mathrm{~mm}$ inner diameter and $0.6 \mathrm{~mm}$ outer diameter, connected to a U-tube manometer with gauge fluid to be ethyl alcohol. A Pitot tube is attached to a rigid two-dimensional traverse; with a resolution of $0.1 \mathrm{~mm}$ in linear translation. In all measurements, the sensing probe stem was kept normal to the jet axis with its sensing hole facing the flow. Further details regarding the Pitot tube is available in Ref. ${ }^{23,24}$ Since, the subsonic jet is always perfectly expanded; the static pressure in the jet field is the same that of back pressure (atmospheric pressure). The velocity in the jet field is calculated from the measured total pressure using the Equation 1, where, $\mathrm{p}_{0}$ is the Pitot pressure, $\rho_{\mathrm{x}}=\rho_{\mathrm{atm}}$, since the jet is incompressible.

$$
V_{x}=\sqrt{\frac{2\left(p_{0}-p_{a t m}\right)}{\rho_{x}}}
$$

Flow visualization is a powerful tool to qualitatively study the behavior and the physics behind the fluid movement. Titanium tetrachloride, commonly used as a smoke-producing chemical when exposed to air, is injected into the stagnation chamber. The flow along with smoke particles of size $1 \mu \mathrm{m}$, which issues out of the nozzle exit is illuminated by the laser sheet of $1 \mathrm{~mm}$ thickness. The laser sheet was produced by dispersing the laser beam through a cylindrical lens. The flow images are captured at a framing rate of 30 images per second.

\section{Results and discussion}

It is well established that the centreline velocity measurement is an authentic measure to quantify the potential core-length, the characteristic decay and the far-field decay of the jet. ${ }^{19}$ Centreline velocity can show the extent of potential core; measure of constant velocity along the jet axis. Shorter the core length better is the jet mixing with the ambient. Figure 3, shows the variation of nondimensionalized centerline velocity $\left(\mathrm{U}_{\mathrm{x}} / \mathrm{U}_{\mathrm{e}}\right)$ as function of non- 
dimensionalized axial distance (x/D). It is seen that the potential core for the conventional circular nozzle of the present study is about 3D, which is lesser than that of $5 \mathrm{D}$, observed by Bradbury \& Khadem $^{19}$ for a Reynolds number of $6^{*} 10^{5}$. The reason for the reduced potential core length of the present study is that, the decay rate of the normalized centerline velocity decreased with increase in Reynolds number. ${ }^{33}$ As also, seen in Figure 3, the decay of the centerline velocity is faster for the rectangular jet at Reynolds number of about $15,000^{34}$ than $54,000 .{ }^{35}$ An important parameter to be considered in the jet field, is the nature of the nozzle, which is a conventional conical nozzle in the present study when compared to the contoured nozzle of Bradbury \& Khadem. ${ }^{19} \mathrm{~A}$ jet issuing out of the conventional conical nozzle will decay and diffuse much earlier than the jet from the contour nozzle. The same kind of observation can be seen for a jet from the circular conical and contoured nozzle, at $\mathrm{Re}=15,000 .{ }^{34}$ The core length of the six and eight tooth chevron nozzles are about $1 \mathrm{D}$ and $1.5 \mathrm{D}$, which is about 67 and $50 \%$ reduction in the core lengths. However, the reduction caused by the six tooth chevron configuration is higher than the eighth tooth chevron configuration.

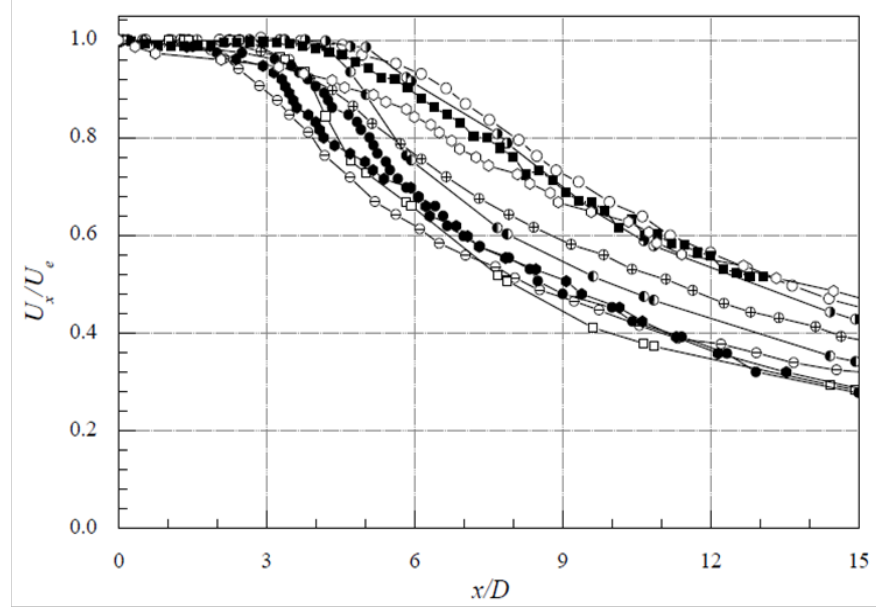

Figure 3 Centreline variations of $U / U$; O-Circular jet (no control; $R e=6 * 10^{5}$ ), ${ }^{19}$ Ө-Circular jet $\left(2\right.$ tabs; $\left.\operatorname{Re}=6 * 10^{5}\right),{ }^{19} \oplus$-Circular jet $\left(4\right.$ tabs; $\left.\operatorname{Re}=6 * 10^{5}\right),{ }^{19}$ -Circular jet (Plain, $R e=15,000),{ }^{34}$-Circular jet (Contoured, $\left.R e=15,000\right){ }^{34}$ $\square$-Rectangular jet $(\mathrm{Re}=15,000),{ }^{34}$-Rectangular jet $(\mathrm{Re}=54,000),{ }^{35} \cdot$-Circular jet (no control, $\mathrm{Re}=25,000)$, - -Chevron (6 tooth, $\mathrm{Re}=25,000), \square$-Chevron (8 tooth, $\operatorname{Re}=25,000)$.

Thus, it can be stated that the six tooth chevron nozzle enhances mixing of the jet with the ambient. It is also seen that the potential core length and the decay rate of the jets for; six tooth chevron nozzle, rectangular nozzle $(\mathrm{Re}=15,000),{ }^{34}$ and the two tab circular nozzle, ${ }^{19}$ are almost the same. A point to be noted is that the Reynolds number of the rectangular nozzle $(\operatorname{Re}=15,000)^{34}$ is less than the chevron configuration $(\mathrm{Re}=25,000)$. This implies that the mixing promoting efficiency of all these three jets are identical; whereas the tab results in momentum loss. ${ }^{18}$ This reveals the superiority of the chevron configuration over the rectangular and tabbed jets. Moreover, the chevron configuration enhances mixing than the conventional conical nozzle; and the six tooth chevron nozzle has a higher decay rate than the eight tooth chevron. Thus it can be brought-out that the number of the chevron tooth has a pronounced effect on the mixing characteristics. To get an insight of the jet development, laser flow visualization has been performed at the near-field of the jet at $x / D=0$ (Figure 4 ) and $\mathrm{x} / \mathrm{D}=3$ (Figure 5 ). At the very near field of the jet at $\mathrm{x} /$ $\mathrm{D}=0$, the circular shape of the jet is retained for the circular nozzle as seen in Figure 4A, whereas for the six and eight tooth chevron, the six and eight lobe structure (Figure 4B) (Figure 4C) are seen.

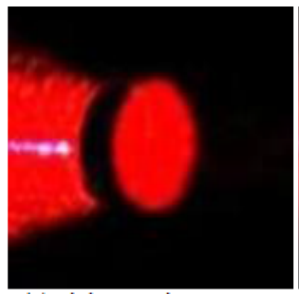

(a) Plain nozzle

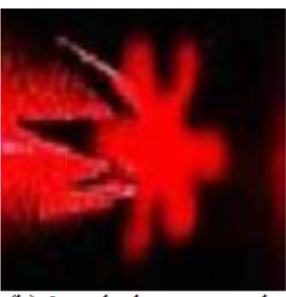

(b) 6 tooth chevron nozzle

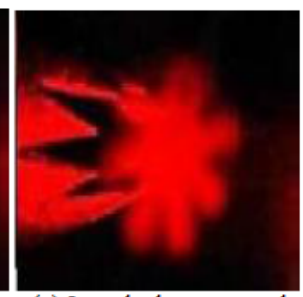

(c) 8 tooth chevron nozzle
Figure 4 Smoke flow visualization of the jets at $\operatorname{Re}=25,000$ at a axial location of $x / D=0$.

It is also seen that the spread for the chevron nozzles is higher than that of conventional circular nozzle. As the axial distance from the nozzle exit increases, the flow pattern enlarges indicating increased mass entrainment along the downstream direction. The spread for the chevron nozzles (Figure 5B) (Figure 5C) is higher than the circular nozzle (Figure 5A), as a result of rapid mixing caused by chevron structures. Jet from the circular nozzle shows a circular structure (Figure $5 \mathrm{~A}$ ) at $\mathrm{x} / \mathrm{D}=3$. Axi-symmetric circular structure is seen for the eight tooth chevron, revealing the jet has diffused and the mixing promoting capability has been lost. Whereas, for the six tooth chevron nozzle, the non-axisymmetric structure of the jet is still retained, implying a better mixing promoting capability of the six tooth chevron over eight tooth chevron nozzle flows, justifying the discussion made with respect to Figure 3. Thus it can be stated that the non-axisymmetric structure of the jet results in enhanced mixing of the jet.

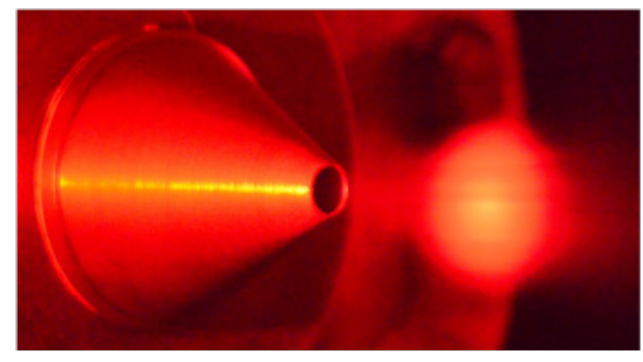

(a) Uncontrolled jet

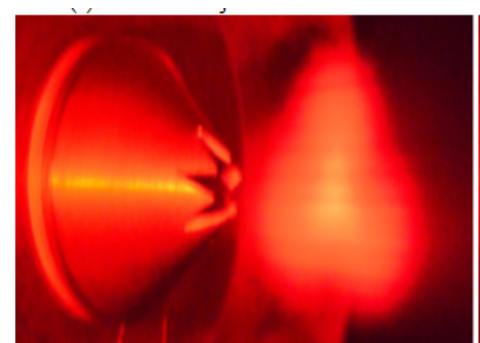

(b) Chevron with 6 tooth

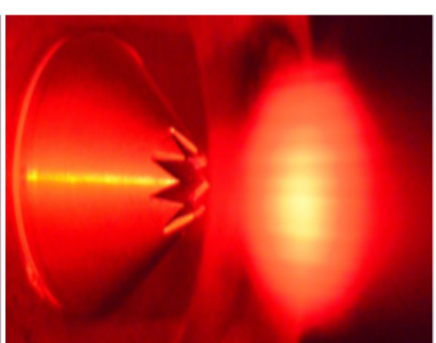

(c) Chevron with 8 tooth
Figure 5 Smoke flow visualization of the jets at $\operatorname{Re}=25,000$ at a axial location of $x / D=3$.

\section{Conclusion}

Near field analysis of jet flow characteristics of chevron has shown enhancement in mixing when compared with a conventional conical nozzle. The distortion of axisymmetric nature of the jet is responsible for increasing mixing. In the case of eight tooth configuration, the 
eight lobe structure at the very close proximity of the exit, transforms to circular structure at $\mathrm{x} / \mathrm{D}=3$, leading to axi-symmetric structure. However, six lobe structure of the six tooth chevron, transform to a three lobe structure (non-axisymmetric) at $\mathrm{x} / \mathrm{D}=3$. It is also evident from the Pitot measurement that, the reduction in potential corelength is higher for the six tooth chevron that the eight tooth chevron. Thus it can be concluded that, the non-axisymmetric structure of the jet results in enhanced mixing of the jet. Moreover, it is also found that the number of the chevron tooth has a pronounced effect on the mixing characteristics.

\section{Acknowledgements}

We acknowledge Amrita School of Engineering, Coimbatore, for providing funding and technical assistance for this research study. Specifically, we also thank Mr. Aswin Reddy, Ms. Sruthy and Mr. Sridharan, undergraduate students of Aerospace Engineering, Amrita School of Engineering, Coimbatore.

\section{Conflict of interest}

None.

\section{References}

1. Gutmark EJ, Schadow KC, Yu KH. Mixing enhancement in supersonic free shear flows. Annu Rev Fluid Mech. 1995;27:375-417.

2. Gutmark EJ, Grinstein FF. Flow Control with Non-Circular Jets. Annu Rev Fluid Mech. 1999;31:239-272.

3. Seiner JM, Dash SM, Kenzakowski DC. Historical survey on enhanced mixing in scramjet engines. Journal of Propulsion and Power. 2001;17:1273-1286.

4. Glezer A, Michael A. Synthetic jets. Annu Rev Fluid Mech. 2002;34:503-529.

5. Reynolds WC, Parekh DE, Juvet PJD, et al. Bifurcating and blooming jets. Annu Rev Fluid Mech. 2003;35:295-315.

6. Ginevsky AS, Ye V Vlasov, Karavosov RK. Acoustic control of turbulent jets. Springer Science \& Business Media: Switzerland; 2004. 235p.

7. Knowles K, Saddington AJ. A review of jet mixing enhancement for aircraft propulsion applications. Proceedings of the Institution of Mechanical Engineers, Part G: Journal of Aerospace Engineering. 2006;220(2):103-127.

8. Henderson B. Fifty years of fluidic injection for jet noise reduction. International Journal of Aeroacoustics. 2010;9(1-2):91-122.

9. Davis MR. Variable Control of Jet Decay. AIAA Journal. 1982;20(5):606-609.

10. Behrouzi P, Feng T, Mc Guirk JJ. Active Flow Control of Jet Mixing Using Steady and Pulsed Fluid Tabs. Proceedings of the Institution of Mechanical Engineers, Part I: Journal of Systems and Control Engineering. 2008;222(5):381-391.

11. Nicolas C, Sebastien D, Laurent J. Numerical Study of Mixing Enhancement in a Supersonic Round Jet. AIAA Journal. 2007;45(7):1675-1687.

12. Nicolas C, Sebastien D, Laurent J. Shock Patterns in a Slightly under expanded Sonic Jet Controlled by Radial Injections. Physics of Fluids. 2007;19(4):048104

13. Yu SCM, Lim KS, Chao W, et al. Mixing Enhancement in Subsonic Jet Flow Using the Air-Tab Technique. AIAA Journal. 2008;46(11):2966-2969.

14. Wan C, Yu SCM. Investigation of Air Tabs Effect in Supersonic Jets.
Journal of Propulsion and Power. 2011;27(5):1157-1160.

15. Wan C, Yu SCM. Numerical Investigation of the Air Tabs Technique in Jet Flow. Journal of Propulsion and Power. 2013;29(1):42-49.

16. Muhamman AK, Mc Guirk JJ. Subsonic Jet Mixing via Active Control Using Steady and Pulsed Control Jets. AIAA Journal. 2011;49(4):712-724.

17. Arun Kumar P, Verma SB, Rathakrishnan E. Experimental Study of Subsonic and Sonic Jets Controlled by Air Tabs. Journal of Propulsion and Power. 2015;38(6):1-9.

18. Zaman KBMQ. Spreading characteristics of compressible jets from nozzles of various geometries. Journal of Fluid Mechanics. 1999;383:197-228.

19. Bradbury LJS, Khadem AH. The Distortion of a Jet by Tabs. Journal of Fluid Mechanics. 1975;70(4):801-813.

20. Samimy M, Zaman KBMQ, Reeder MF. Effect of Tabs on the Flow and Noise Field of an Axisymmetric Jet. AIAA Journal. 1993;31(4):609-619.

21. Zaman KBMQ. Streamwise Vorticity Generation and Mixing Enhancement in Free Jets by Delta-Tabs. AIAA Sher Flow conference: Florida; 1993. 15p.

22. Zaman KBMQ, Reeder MF, Samimy M. Control of an Axisymmetric Jet Using Vortex Generators. Physics of Fluids. 1994;6(2):778-793.

23. Arun Kumar P, Rathakrishnan E. Truncated Triangular Tabs for Supersonic Jet Control. Journal of Propulsion and Power. 2013;29(1):50-65.

24. Arun KumarP, Rathakrishnan E. Triangular Tabs for Supersonic Jet Mixing Enhancement. The Aeronautical Journal. 2014;118(1209):1245-1278.

25. Callender B, Ephraim JG, Steve M. Far-field acoustic investigation into chevron nozzle mechanisms and trends. AIAA Journal. 2005;43(1):87-95.

26. Uzun A, Hussaini MY. Noise generation in the near-nozzle region of a chevron nozzle jet flow. $13^{\text {th }}$ AIAA/CEAS Aeroacoustics Conference: Florida; 2007. 37p

27. Callender B, Gutmark E, Martens S. Near-field investigation of chevron nozzle mechanisms. AIAA Journal. 2008;46(1):36-45.

28. Schlinker RH, Simonich JC, Sharon DW, et al. Supersonic jet noise from round and chevron nozzles: Experimental studies. $30^{\text {th }}$ AIAA Aeroacoustics Conference: Florida; 11-13 May 2009. 22p.

29. Zaman KBMQ, Bridges JE, Hu_ DL. Evolution from 'Tabs' to 'Chevron Technology a Review. International Journal of Aeroacoustics. 10(5-6):685-709.

30. Rask O, Kastner J, Gutmark E. Understanding How Chevrons Modify Noise in Supersonic Jet with Flight Effects. AIAA Journal. 2011;49(8):1569-1576.

31. Munday D, Nick H, Ephraim G, et al. Acoustic Effect of Chevrons on Supersonic Jets Exiting Conical Convergent-Divergent Nozzles. AIAA Journal. 2012;50(11):2336-2350.

32. Tide PS, Srinivasan K. Effect of chevron count and penetration on the acoustic characteristics of chevron nozzles. Applied Acoustics. 2010;71(3):201-220.

33. Malmstrm TG, Kirkpatrick AT, Christensen B, et al. Centreline velocity decay measurements in low-velocity axisymmetric jets. Journal of Fluid Mechanics. 1977;346:363-377.

34. Mi J, Nathan GJ, Luxton RE. Centreline mixing characteristics of jets from nine differently shaped nozzles. Experiments in Fluids. 2000;28(1):93-94.

35. Arun Kumar P, Verma SB, Elangovan S. Study of jets from rectangular nozzles with square grooves. Aeronautical Journal: Royal society of London. 2011;115(1165):187-196. 